\title{
Fluoxetine Alleviates Behavioral Depression while Decreasing Acetylcholine Release in the Nucleus Accumbens Shell
}

\author{
David T Chau* ${ }^{*, 1,2}$, Pedro V Rada ${ }^{1,3}$, Kay Kim ${ }^{1,4}$, Rebecca A Kosloff ${ }^{1,5}$ and Bartley G Hoebel ${ }^{1,6}$ \\ 'Department of Psychology, Princeton University, Princeton, NJ, USA; ${ }^{2}$ College of Medicine, University of Vermont, Burlington, VT, USA; ${ }^{3}$ Laboratory \\ of Behavioral Physiology, School of Medicine, University of Los Andes, Mérida, Venezuela; ${ }^{4}$ Cornell University College of Veterinary Medicine, \\ Ithaca, NY, USA; ${ }^{5}$ Florida Cancer Specialists, Naples, FL, USA; ${ }^{6}$ Princeton Neuroscience Institute, Princeton University, Princeton, NJ, USA
}

\begin{abstract}
Selective serotonin reuptake inhibitors, such as fluoxetine, have demonstrated the ability to alleviate behavioral depression in the forced swim test; however, the sites and mechanisms of their actions remain to be further elucidated. Previous studies have suggested that behavioral depression in the swim test is mediated in part by acetylcholine (ACh) stimulating the cholinergic MI receptors in the nucleus accumbens (NAc) shell. The current study tested whether acute, local, and chronic, subcutaneous fluoxetine treatments increase escape motivation during the swim test while simultaneously lowering extracellular ACh in the NAc shell. Experiment I: Fluoxetine (I.0 mM) infused unilaterally in the NAc shell for 40 min reduced extracellular ACh while simultaneously increasing swimming time. Experiment 2: Fluoxetine $(0.2,0.5$, and $0.75 \mathrm{mM})$ infused bilaterally in the NAc shell on day 3 dose-dependently decreased immobility and increased the total escape attempts (swimming and climbing) compared with Ringer given on day 2. Experiment 3: Fluoxetine (0.5 mM) infused bilaterally in the NAc for 40 min did not affect activities in an open field. Experiment 4: Chronic systemic fluoxetine treatment decreased immobility scores and increased total escape attempt scores compared with control saline treatment. In all, I 4 days after the initial swim test, basal extracellular ACh in the shell was still elevated in the saline-treated group, but not in the fluoxetine-treated group. In summary, these data suggest that one of the potential mechanisms by which fluoxetine alleviates behavioral depression in the forced swim test may be to suppress cholinergic activities in the NAc shell.

Neuropsychopharmacology (20II) 36, 1729-1737; doi:I0.1038/npp.201।.54; published online 27 April 201।
\end{abstract}

Keywords: depression; fluoxetine; acetylcholine; nucleus accumbens; swim test; rat

\section{INTRODUCTION}

Central cholinergic transmission has long been known to be involved in depression (Dilsaver, 1986; Janowsky et al, 1983); however, it is unclear which specific cholinergic systems are involved and how they are affected by antidepressant treatments. Cholinergic interneurons intrinsic in the nucleus accumbens (NAc) are potentially an important target for antidepressant treatments (Chau et al, 2001; Hoebel et al, 2007; Rada et al, 1993, 2006). These neurons are the sole source of local acetylcholine (ACh) in the NAc. Their perikarya are lightly scattered in core, but in the shell subregion, they are densely packed to form a cell column that runs in the rostrocaudal direction (Meredith et al, 1989). They have extensive axonal arborization and many of their terminals form synapses (largely excitatory via M1 muscarinic receptors) on the dendrites- and cell

*Correspondence: Dr DT Chau, University of Vermont College of Medicine, Given Box No. 105, 89 Beaumont Avenue, Burlington, VT 05405-0068, USA. Tel: 603276 5943, E-mail: dchau@uvm.edu Received 15 October 20 10; revised I March 20 I ; accepted 21 March 2011 bodies of the medium spiny $\gamma$-aminobutyric acidcontaining output neurons (Phelps and Vaughn, 1986). These cholinergic interneurons also form an extensive network of extrasynaptic varicosities (denser than elsewhere in the brain) through which the ACh they release may influence glutamateric and dopaminergic inputs and $\gamma$-aminobutyric acidergic output of the accumbens by 'volume' transmission (Descarries et al, 1997).

Our previous data suggest that ACh opposes the action of dopamine (DA) in the control of the accumbens $\gamma$-aminobutyric acid output systems for approach and avoidance behavior (Hoebel et al, 2007). We found that ACh release in the NAc (especially in the posterior medial NAc, ie, the shell) is a correlate or a cause of meal satiation (Avena et al, 2006; Mark et al, 1992), conditioned taste avoidance (Mark et al, 1995), escape from aversive brain stimulation (Rada and Hoebel, 2001), and anxiety during the state of drug withdrawal (Rada et al, 1991, 1996) and sugar withdrawal (Avena et al, 2008). Basal ACh level in the accumbens shell also rises as a correlate of behavioral depression in the forced swim test (Rada et al, 2006). Such elevation in basal ACh coincided with a partial compensatory increase in acetylcholinesterase and a compensatory decrease in 
muscarinic (M1) receptors and their gene expression, suggesting that elevated basal $\mathrm{ACh}$ results in an increase in M1 receptor stimulation (Rada et al, 2006). In another study, local injection of a nonspecific muscarinic agonist in the accumbens shell exacerbated behavioral depression in the swim test and local injection of an M1 antagonist alleviated it (Chau et al, 2001). Moreover, local injections of M2 autoreceptor antagonists increased ACh outflow and increased behavioral depression (Chau et al, 2001). These data, taken together, suggest that behavioral depression in the swim test is partly mediated by hyperstimulation of M1 receptors in NAc shell.

Selective serotonin reuptake inhibitors (SSRIs) belong to one of the most effective and commonly used class of antidepressants; therefore, it is important to investigate how they may affect cholinergic transmission in NAc during depression. Anatomical studies have shown that the accumbens is innervated by the serotonergic neurons from both the mesencephalic raphe nuclei and the midbrain periaqueductal gray (Li et al, 1989; Steinbusch, 1981). These serotonergic projections form symmetric, inhibitory synaptic contacts with cholinergic interneurons in the shell more frequently than with those in the core (Van Bockstaele et al, 1996; Van Bockstaele and Pickel, 1993). Both acute and chronic systemic SSRI treatments (including fluoxetine) have been shown to elevate extracellular levels of serotonin (5-HT) in the ventral striatum and NAc (Guan and McBride, 1988; Kirby and Lucki, 1997; Shen et al, 2004). In a previous study, we showed that when fluoxetine or 5-HT was infused into the posterior medial NAc, it significantly lowered extracellular ACh (Rada et al, 1993).

The current study assessed the ability of fluoxetine to alleviate behavioral depression in the forced swim test and whether such an effect of fluoxetine is associated with changes in extracellular ACh in the NAc shell. Three approaches were taken. First, we examined whether fluoxetine infused unilaterally into the NAc shell increases escape efforts in the swim test while lowering extracellular ACh. Second, we measured whether fluoxetine infused bilaterally into the same region also increases escape efforts. Third, we assessed the selectivity of such local bilateral fluoxetine treatment on escape effort as opposed to locomotor activity by determining whether it causes hyperactivity in the open field. Finally, we addressed the basis of the delayed therapeutic action of SSRIs in humans by assessing whether chronic, systemic fluoxetine treatment increases escape efforts in the swim test while decreasing basal extracellular ACh in the NAc shell.

\section{MATERIALS AND METHODS}

\section{Animals and Surgery}

Female, Sprague-Dawley rats $(250-350$ g, Taconic Farms, Germantown, NY) were housed individually on a reversed $12: 12 \mathrm{~h}$ light-dark schedule. Female rats were used because they express higher levels of immobility than males in the swim test (Drossopoulou et al, 2004) and were previously used to demonstrate the role of cholinergic receptors in the mediation of behavioral depression in the swim test (Chau et al, 2001).
All rats were implanted bilaterally with stainless steel guide shafts (21 ga) to serve as guides for microdialysis probes or drug injectors. Coordinates for the guide shafts were B: $+1.2 \mathrm{~mm}, \mathrm{~V}: 4 \mathrm{~mm}$, and L: $1.2 \mathrm{~mm}$, with reference to bregma, level surface of the skull, and mid-sagittal sinus (Paxino and Watson, 1997). Rats were maintained under anesthesia during surgery using xylazine $(10 \mathrm{mg} / \mathrm{kg}$, i.p.) plus ketamine $(80 \mathrm{mg} / \mathrm{kg}$, i.p.) or phentobarbital $(20 \mathrm{mg} / \mathrm{kg}$, i.p.) supplemented with ketamine $(40 \mathrm{mg} / \mathrm{kg}$, i.p.). Animals were allowed to recover for at least 7 days before testing. All tests were conducted between the twelfth and eighteenth hour during the dark cycle. Experiments were carried out in accordance with the Guide for the Care and Use of Laboratory Animals as adopted by the U.S. National Institute of Health, and were approved by the Princeton University Animal Care and Use Committee.

\section{Swim Test Protocol}

During the pretest (day 1), rats were placed individually in an opaque polypropylene, cylindrical water tank (diameter $27 \mathrm{~cm}$; height $42 \mathrm{~cm}$; water depth $33 \mathrm{~cm} ; 25-30^{\circ} \mathrm{C}$ ) for 10 or $15 \mathrm{~min}$. All rats underwent 10 -min swim tests on subsequent days in which the effects of $\operatorname{drug}(s)$ and or vehicle were assessed by a rater blind to the treatments. For all experiments involving fluoxetine (except Experiment 1), behaviors in the swim test were scored using the timesampling technique (Detke et al, 1995). During every 5-s interval, the rater determined which behavior (climbing, swimming, diving, or immobile) dominated, and incremented its score by one. In other experiments, the total swimming time was recorded. Swimming time was defined as the length of time (sec) rats engaged in climbing, swimming, or diving (Chau et al, 2001).

\section{Experiment 1: Determining the Effects of Local, Unilateral Fluoxetine Administration on Accumbens ACh Levels and Swimming Time}

Microdialysis probe implant and ACh detection. A probe was implanted in either the left or right medial posterior NAc in counterbalanced order $12 \mathrm{~h}$ before the pretest, according to the methods of Rada et al (1993) $(N=8)$. Coordinates for the probes were $\mathrm{B}:+1.2 \mathrm{~mm}, \mathrm{~V}: 7-10 \mathrm{~mm}$, and L: $\pm 1.2 \mathrm{~mm}$ (Paxino and Watson, 1997). As there is no laterality effect from the fluoxetine infusion on either extracellular ACh (Rada et al, 1993) or immobility scores (see Results below), it was not necessary here to examine each side of the brain individually.

Probes were perfused with a modified Ringer (Chau et al, 2001) $0.5 \mu \mathrm{l} / \mathrm{min}$ overnight and $2.0 \mu \mathrm{l} / \mathrm{min}$ during sample collection. A low dose of neostigmine $(0.3 \mu \mathrm{M}$; Sigma Chemical, St Louis, MO), which had no effect on behavior, was added to the perfusate to increase the recovered $\mathrm{ACh}$, which was separated by reversed phase, high-performance liquid chromatography (Chau et al, 2001).

Swimming. All rats underwent a 10 -min pretest (day 1 ) and two 10-min swim tests conducted $24 \mathrm{~h}$ (day 2 ) and $48 \mathrm{~h}$ later (day 3). The swimming time (sec) during each session was recorded. 
Treatment. Fluoxetine was administered by intercalating into the perfusion line a preloaded section of tubing to produce a timed pulse of the drug. On days 2 and 3, all rats received a $40-\mathrm{min}$ pulse of fluoxetine $(1.0 \mathrm{mM}$ in Ringer; Eli Lilly, Indianapolis, IN) and a 40-min pulse of Ringer in counterbalanced order. Previous estimates suggest that about $10 \%$ of fluoxetine in the perfusate may diffuse out into the extracellular space (Hernandez et al, 1991). Swimming sessions occurred during the last $10 \mathrm{~min}$ of the infusions.

Dialysate sample collection. Following the procedure of Rada et al (1993), 20 samples of 5 min each were collected: 6 during baseline; 8 during perfusion of Ringer or fluoxetine; and 6 afterward. The relative ACh levels were recorded and expressed as percentages of the baseline.

\section{Experiment 2: Determining the Effects of Local, Bilateral Fluoxetine Administration on Behavior During the Swim Test}

A total of 26 rats underwent a 15 -min pretest in the swim tank. Two microdialysis probes were bilaterally implanted in the posterior medial NAc $12 \mathrm{~h}$ following the pretest. The coordinates of the probes were B: $+1.2 \mathrm{~mm}, \mathrm{~V}: 7-9 \mathrm{~mm}$, and L: $\pm 1.2 \mathrm{~mm}$ (Paxino and Watson, 1997). Both probes were perfused with a modified Ringer $0.5 \mu \mathrm{l} / \mathrm{min}$ overnight. Rats were divided into three treatment groups $(N=7-8$ per group), each received a 40 -min pulse of fluoxetine $(0.2,0.5$, or $0.75 \mathrm{mM}$ in the perfusate) and a 40 -min pulse of Ringer on another day in counterbalanced order (either on day 2 or day 3). The flow rate during the infusions was $1.0 \mu \mathrm{l} / \mathrm{min}$. In the last $10 \mathrm{~min}$ of the 40 -min pulses, rats were placed in the swim tank and their behaviors were scored using the timesampling method (Detke et al, 1995).

\section{Experiment 3: Determining the Effects of Local, Bilateral Fluoxetine Administration on Locomotor Activity in the Open Field}

Microdialysis probes were bilaterally inserted in the posterior medial NAc $(N=6) 12 \mathrm{~h}$ before the activity tests. The perfusion rates and probe coordinates were identical to those used in the swim tests. All rats received a 40-min pulse of fluoxetine $(0.5 \mathrm{mM}$ in the perfusate) and of Ringer on two consecutive days in counterbalanced order. In the last $10 \mathrm{~min}$ of the infusions, rats were placed in an activity monitoring, photocell chamber (Med Associates, St Albans, VT). The following indices of activity were recorded: distance traveled, ambulatory time, vertical time, stereotypic time, and resting time.

\section{Experiment 4: Determining the Effects of Chronic, Systemic Fluoxetine Administration on Basal Extracellular ACh in the NAc}

Swim tests and drug treatments. In all, 13 rats underwent a 15 -min pretest. In the next 15 days, they received either daily, systemic fluoxetine injections $(N=7 ; 5.0 \mathrm{mg} / \mathrm{kg}$ dissolved in $1.0 \mathrm{ml}$ deionized water per $\mathrm{kg}$, s.c.) or daily saline injections $(N=6 ; 1.0 \mathrm{ml} / \mathrm{kg}$, s.c.). Rats underwent a 10 -min swim test $1 \mathrm{~h}$ following the fifteenth injection, and their behaviors were scored using the time-sampling method (Detke et al, 1995).

Microdialysis. A microdialysis probe was implanted in either the left or right NAc at the same coordinates used in Experiment 1, $12 \mathrm{~h}$ following the pretest. A stable ACh baseline, consisting of at least three 20-min dialysate samples ( $\pm 10 \%$ SEM $), 23 \mathrm{~h}$ after the pretest was established before the first fluoxetine injection. Six 20-min, postinjection samples were collected. Immediately afterward, the probe was removed and a stainless steel obdurator was reinserted into the guide shaft to keep the microdialysis site patent. A new probe was inserted at the same site $16 \mathrm{~h}$ before the fourteenth daily injection. Three 20-min samples were collected before the fourteenth injection to establish a new ACh baseline, and 6 additional samples were collected following the injection.

All probes were calibrated before use. They were immersed in a standard ACh solution ( 2 pmole $/ 20 \mu \mathrm{l}$ buffer solution) for $0.5 \mathrm{~h}$, and then the ACh collected in the effluent (20-min samples, $1.0 \mu \mathrm{l} / \mathrm{min})$ was quantified using highperformance liquid chromatography (see Experiment 1). Probes that had an ACh recovery rate $<10 \%$ were not used. Extracellular ACh levels on the first and fourteenth day of the daily injections were calculated using the individual probes' rates of ACh recovery as normalization factors.

\section{Histology}

At the end of experiments, rats were anesthetized and perfused with isotonic saline, followed by $10 \%$ formalin. Brains were sectioned at $40 \mu \mathrm{m}$ and examined microscopically to verify the locations of microdialysis probes.

\section{Data Analysis}

The effects of local treatments on swimming time were compared using paired, $t$-tests. The effects of acute and chronic fluoxetine treatments on behavioral scores rated using the time-sampling method were assessed using 2-way analysis of variances (ANOVAs) with behavioral category (swimming $v s$ climbing $v s$ immobile) and treatment (fluoxetine $v s$ vehicle) as variables. Diving rarely occurred and therefore was not analyzed. Because a majority of the animals tested exhibited very low swimming scores $(\leqslant 15$ out of 120) during both drug and vehicle tests, the sum of swimming and climbing scores was used as an index of general escape effort. The effects of treatments on this index were analyzed using paired, one-tail $t$-tests. The effects of treatments on activity were analyzed using 2-way ANOVA with indices of activity and treatment as variables. The effects of acute and chronic fluoxetine treatment on ACh levels (\% of baseline) were analyzed using 2-way repeated measures ANOVA, with time (dialysate sampling periods) and treatment as variables. Basal extracellular ACh levels in the fluoxetine and vehicle groups were compared using a one-tail paired $t$-test, as well as a $\chi^{2}$-test. All ANOVAs were followed by post-hoc Bonferroni tests as appropriate. Significance was determined at $p<0.05$. Data are expressed as mean $\pm \mathrm{SEM}$. 


\section{RESULTS}

Experiment 1: Local, Unilateral Fluoxetine Administration Lowers ACh Levels in the NAc and Increases Swimming Time

Consistent with earlier observations, ACh levels during and following fluoxetine infusion were substantially lower than levels recorded at similar time points during either Ringer infusion or during the pretest $(p<0.05$, two-way ANOVAs followed by Bonferroni post-hoc tests; see detailed results of the analyses below and Figure 1). Moreover, the swimming time during fluoxetine $(329 \pm 45 \mathrm{~s})$ was $18.9 \%$ greater than during Ringer ( $277 \pm 44 \mathrm{~s}, n=8$; one-tail: $t=1.89, p<0.005$, two-tail: $t=2.36, p<0.007)$. Two-way repeated measures ANOVA indicated significant effects of time $(F(19,399)=$ $22.70, p<0.0001)$ and treatment $(F(2,399)=13.66, p<0.0001)$ on ACh outflow (\% of baseline) in NAc, as well as a treatment by time interaction $(F(38,399)=6.45, p<0.0001)$ (Figure 1). On pretest day (day 1), ACh decreased below baseline during the second half of the swimming session and remained suppressed during the next $30 \mathrm{~min}$ when the rats were removed from the water $(p<0.05)$. On subsequent days (day 2 or day 3 ), during Ringer infusion, ACh again decreased half way into the swim test, but unlike the previous day, ACh remained suppressed for only $15 \mathrm{~min}$ after rats were removed from the water $(p<0.05)$. On the days rats received the fluoxetine treatment, ACh dramatically decreased half way into the fluoxetine infusion and remained strongly suppressed below baseline during rest of the observation period $(p<0.05)$. Between-group comparisons using Bonferroni's tests revealed that changes in extracellular ACh during the Ringer day and the pretest day were not different from each other.

\section{Experiment 2: Local, Bilateral Fluoxetine Administration Increases Escape Efforts During the Swim Test}

Fluoxetine $(2,5$, and $7.5 \mathrm{mM})$ was infused bilaterally in the NAc in three separate groups of rats ( $n=8-9$ per group). As described in methods, each group of rats received only one dose of fluoxetine, and fluoxetine was counterbalanced with Ringer in the same rat between day 2 and day 3. Thus,

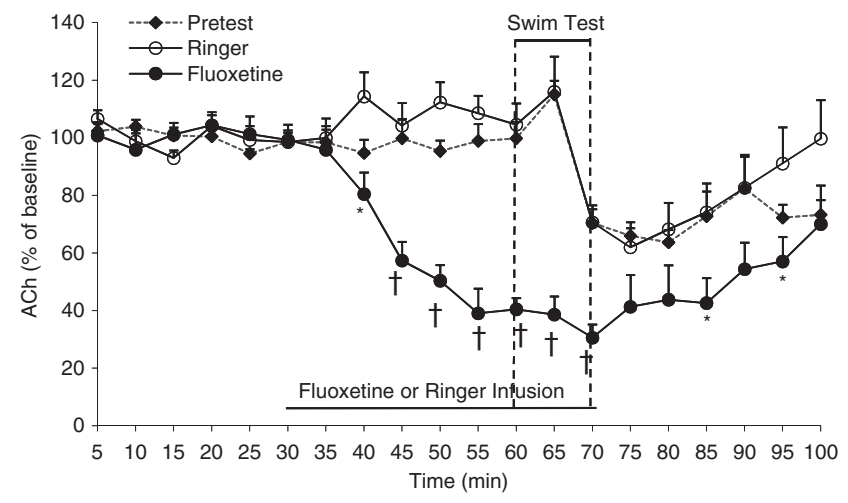

Figure I Effects of local fluoxetine administration on ACh outflow in the NAc during the pretest and the swim tests. ${ }^{*} p<0.05$; ${ }^{\dagger} p<0.00$ I, compared with Ringer. The ACh levels are expressed as percentages of baseline and not in pmole, because absolute levels were not recorded in this experiment. half of the subjects within each group received one of the three doses of fluoxetine on day 2 and Ringer on day 3 of the swim test; the other half in each group received the respective dose of fluoxetine and Ringer in the reserved order (ie, fluoxetine on day 3 and Ringer on day 2). Data from both groups were combined and analyzed together. When examining the data in this manner, only the middle dose $(5 \mathrm{mM})$ shows a significant increase in the total escape responses (ie, swimming plus climbing scores), relative to Ringer $(n=9, t=1.94, p<0.05)$ (Table 1$)$.

Subsequently, data from animals receiving fluoxetine on day 3 and Ringer on day 2 were analyzed separately. This secondary analysis was done to control for the possibility that fluoxetine could have affected swimming behavior the next day. For this secondary analysis, we hypothesized that the total escape responses would be greater during fluoxetine than during Ringer if fluoxetine was given on day 3 (but not on day 2). Consistent with this hypothesis, two-way ANOVA revealed that all doses of fluoxetine given on day 3 (but not on day 2) increased the total escape responses (fluoxetine on day $3 v s$ Ringer on day 2: $2 \mathrm{mM}$, $n=5, \quad t=2.6, \quad p<0.05 ; \quad 5 \mathrm{mM}, \quad n=5, \quad t=2.39, \quad p<0.05$; $7.5 \mathrm{mM}, n=5, t=2.65, p<0.05$ ) (Tables 2 and 3 ).

\section{Experiment 3: Local, Bilateral Fluoxetine Administration does not Alter Locomotor Activity in the Open Field}

None of the measures related to activity (ambulation, stereotypy, rest, and vertical movement) recorded during bilateral fluoxetine infusion $(0.5 \mathrm{mM}$ per side) in the NAc was different from that seen during control Ringer infusion. This applies to rats that received fluoxetine the day before or after Ringer.

\section{Experiment 4: Chronic, Systemic Fluoxetine Administration Lowers Basal Extracellular ACh Levels in the NAc}

Chronic fluoxetine treatment counteracted the rise in basal extracellular ACh that otherwise followed a swim 2 weeks earlier. Basal extracellular ACh level tended to rise, following a swim in the control group that received chronic, daily saline treatment (after pretest/before treatment: $n=4$, $1.52 \pm 0.3$ pmol; after 14 days of treatment: $4.22 \pm 1.47 \mathrm{pmol}$; $t=2.1, p=0.06)$. However, no change in basal extracellular ACh occurred following chronic fluoxetine treatment (after pretest/before treatment: $n=4,2.80 \pm 0.9 \mathrm{pmol}$; after 14 days of treatment: $2.37 \pm 2.01$ pmol, n.s.) (Figure 2). A $\chi^{2}$-test further suggested that chronic fluoxetine and chronic saline treatment had opposing effects on the basal extracellular ACh levels, that is, saline allowed it to rise, whereas fluoxetine kept it stable $\left(p<0.0001, \chi^{2}\right.$ for independence) (see Figure 2). Interestingly, unlike basal ACh (which was chronically elevated following a swim and was normalized by chronic fluoxetine treatment), the minute-to-minute changes in ACh outflow following the fluoxetine injections were not different from those following saline injections. This applied to both the first and the fourteenth injections.

The total escape efforts, as indicated by the aggregate scores of swimming plus climbing, in the two treatment groups showed significant differences: the swimming plus 
Table I Effects of Local Fluoxetine Administration on Day 2 or 3 of the Swim Test

\begin{tabular}{|c|c|c|c|c|c|c|c|c|c|}
\hline Dose & $n$ & FLU & Ringer & FLU & Ringer & FLU & Ringer & FLU & Ringer \\
\hline $0.2 \mathrm{mM}$ & 8 & $53 \pm 12$ & $62 \pm 10$ & $14 \pm 7$ & $6 \pm 3$ & $52 \pm 10$ & $47 \pm 11$ & $66 \pm 12$ & $52 \pm 9$ \\
\hline $0.5 \mathrm{mM}$ & 9 & $51 \pm 8$ & $59 \pm 9$ & $7 \pm 3$ & $4 \pm 2$ & $61 \pm 9$ & $56 \pm 9$ & $68 \pm 8 *$ & $60 \pm 9$ \\
\hline $0.75 \mathrm{mM}$ & 9 & $53 \pm 7$ & $61 \pm 6$ & $10 \pm 4$ & $7 \pm 3$ & $57 \pm 9$ & $51 \pm 6$ & $67 \pm 7$ & $58 \pm 6$ \\
\hline
\end{tabular}

* $P<0.05$, compared with Ringer.

Fluoxetine was counterbalanced by Ringer on an alternate day.

Table 2 Effects of Local Fluoxetine Administration on Day 3 of the Swim Test

\begin{tabular}{|c|c|c|c|c|c|c|c|c|c|}
\hline \multicolumn{2}{|c|}{ Fluoxetine (FLU) on day 3} & \multicolumn{2}{|c|}{ Immobility } & \multicolumn{2}{|c|}{ Swimming } & \multicolumn{2}{|c|}{ Climbing } & \multicolumn{2}{|c|}{ Swimming+climbing } \\
\hline Dose & $n$ & FLU & Ringer & FLU & Ringer & FLU & Ringer & FLU & Ringer \\
\hline $0.2 \mathrm{mM}$ & 5 & $45 \pm 13$ & $58 \pm 14$ & $14 \pm 8$ & $6 \pm 4$ & $60 \pm 15$ & $53 \pm 17$ & $74 \pm 13^{*}$ & $58 \pm 15$ \\
\hline $0.5 \mathrm{mM}$ & 5 & $39 \pm 10 *$ & $49 \pm 13$ & $7 \pm 6$ & $3 \pm 2$ & $74 \pm 10$ & $66 \pm 12$ & $81 \pm 9 *$ & $69 \pm 12$ \\
\hline $0.75 \mathrm{mM}$ & 5 & $53 \pm 7 *$ & $68 \pm 10$ & $10 \pm 4$ & $3 \pm 1$ & $57 \pm 9 *$ & $48 \pm 10$ & $73 \pm 11 *$ & $51 \pm 10$ \\
\hline
\end{tabular}

${ }^{*} p<0.05$, compared with Ringer.

Fluoxetine was counterbalanced by Ringer given on day 2 .

Table 3 Effects of local fluoxetine administration on day 2 of the swim test

\begin{tabular}{|c|c|c|c|c|c|c|c|c|c|}
\hline \multicolumn{2}{|c|}{ Fluoxetine (FLU) on day 2} & \multicolumn{2}{|c|}{ Immobility } & \multicolumn{2}{|c|}{ Swimming } & \multicolumn{2}{|c|}{ Climbing } & \multicolumn{2}{|c|}{ Swimming+climbing } \\
\hline Dose & $n$ & FLU & Ringer & FLU & Ringer & FLU & Ringer & FLU & Ringer \\
\hline $2 \mathrm{mM}$ & 3 & $66 \pm 30$ & $68 \pm 16$ & $15 \pm 17$ & $6 \pm 8$ & $39 \pm 12$ & $36 \pm 11$ & $54 \pm 30$ & $43 \pm 5$ \\
\hline $5 \mathrm{mM}$ & 4 & $68 \pm 9$ & $72 \pm 14$ & $6 \pm 3$ & $4 \pm 3$ & $45 \pm 12$ & $44 \pm 12$ & $51 \pm 9$ & $48 \pm 14$ \\
\hline $7.5 \mathrm{mM}$ & 4 & $62 \pm 11$ & $53 \pm 7$ & $14 \pm 7$ & $13 \pm 4$ & $44 \pm 10$ & $54 \pm 7$ & $58 \pm 11$ & $67 \pm 7$ \\
\hline
\end{tabular}

Fluoxetine was counterbalanced by Ringer given on day 3.

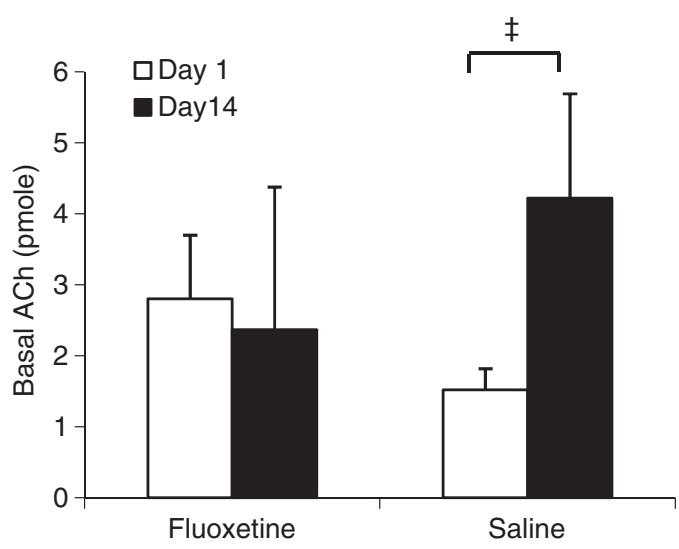

Figure 2 Effects of chronic systemic fluoxetine administration on basal extracellular ACh in the NAc. The data suggest that basal ACh was elevated 2 weeks after the pre-swim in rats injected daily with saline $\left({ }^{\ddagger} p=0.06\right)$. The group treated daily with fluoxetine had a normalized basal ACh level. $A \chi^{2}$-test indicated that chronic fluoxetine and chronic saline had opposing effects on basal ACh ( $p<0.000 \mathrm{I}, \chi^{2}$ for independence).

climbing scores were higher following chronic fluoxetine treatment than following control chronic saline treatment (saline: $42 \pm 11$; fluoxetine: $55 \pm 7 ; t=3.3, p<0.05$ ). As expected, the immobility scores following chronic fluoxetine treatment $(n=3,65 \pm 7)$ showed the opposite trend; they were lower than the scores seen following chronic saline treatment $(n=3,77 \pm 11 ; t=3.3, p<0.05)$.

\section{Histology}

Microdialysis probes were located in the posterior medial NAc, as shown in Figure 3.

\section{DISCUSSION}

The current study assessed the effects of acute, local, and chronic, subcutaneous fluoxetine treatments on extracellular $\mathrm{ACh}$ in the NAc shell, in conjunction with behavioral measurements of escape motivation during the forced swim test. The major findings were as follows: (1) infusion of fluoxetine unilaterally into the NAc shell decreased ACh outflow and simultaneously increased swimming time; (2) infusion of fluoxetine bilaterally into the same brain region also increased escape attempts in the swim test; (3) bilateral fluoxetine did not affect locomotor activity in the open field; and (4) chronic systemic fluoxetine treatment (daily s.c. injection over 14 days) normalized the rise in basal ACh in the NAc shell and increased escape attempts in the swim test. 


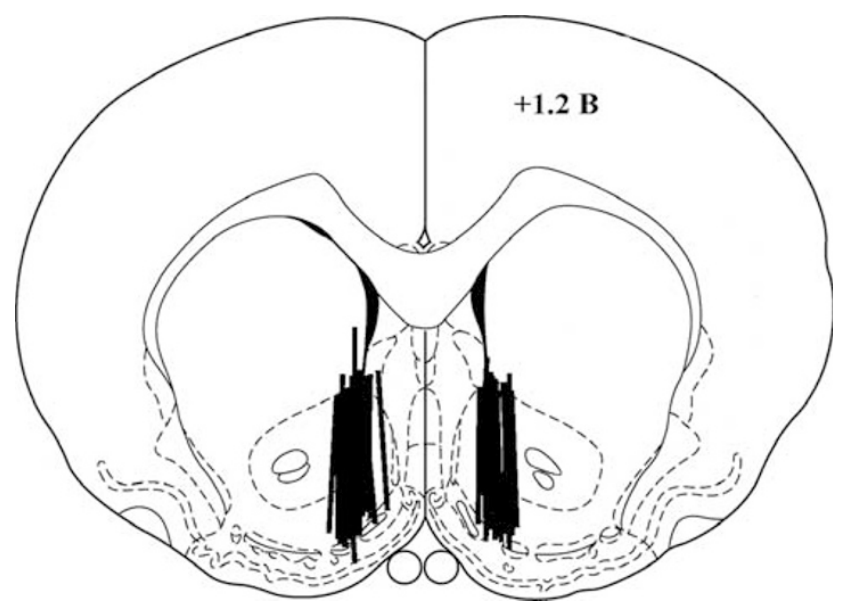

Figure 3 Tracks of microdialysis probes for ACh collection and/or local fluoxetine infusion. Probes are depicted on a cross-section of the rat brain $1.2 \mathrm{~mm}$ anterior to bregma adapted from Paxino and Watson (1997). The last I mm of these cannula tracks corresponds to the cap covering the semipermeable membrane part of the microdialysis probe, causing the actual sites of dialysate collection to be located at least I $\mathrm{mm}$ above the tip of the tracks, in the NAc shell.

In a previous study, we used a reverse microdialysis procedure, identical to that used in the current study, to deliver fluoxetine $(0.05,0.2$, and $1 \mathrm{mM})$ into the NAc shell of freely moving rats and found it to dose-dependently decrease ACh outflow (Rada et al, 1993). In both studies, a specified length of tubing containing the fluoxetine solution was intercalated into the perfusion line to allow the fluoxetine to diffuse out of the probe into the targeted area at a steady rate and over a period of at least $30 \mathrm{~min}$. This procedure is considered a more naturalistic method for local fluoxetine administration than acute microinjection, because it allows the local extracellular 5-HT level to settle to a new steady state and for the metabolites of fluoxetine (eg, norfluoxetine), which have a longer half-life than fluoxetine to contribute to the modulation of ACh outflow (Johnson, 1991; Lemberger et al, 1985; Wong et al, 1975).

In Experiment 1, as in the Rada et al (1993) study, fluoxetine $(1 \mathrm{mM})$ unilaterally infused during $40 \mathrm{~min}$, gradually decreased extracellular $\mathrm{ACh}$ to approximately $40 \%$ of baseline. Our previous study showed in drug-naïve rats that extracellular ACh transiently decreases during the first swimming session (ie, the pretest), then gradually increases over the next few hours and remains high $24 \mathrm{~h}$ later, as rats become behaviorally depressed when tested the second time (Rada et al, 2006). Apparently, elevated basal ACh measured minutes before the second swimming session is a more reliable predictor of behavior depression than the levels of ACh measured during the swim test itself. Therefore, we limited our observation period to the minutes before and during the swim test, but not several hours afterward.

An important new finding here was that fluoxetine infused directly into the NAc shell, simultaneously alleviated behavioral depression in the swim test while decreasing ACh outflow more than Ringer infusion at all time points examined (see Figure 1). This finding is consistent with our cholinergic hypothesis suggesting that a decrease in ACh outflow in the NAc shell would lead to an amelioration of $\mathrm{M} 1$ receptor stimulation and alleviation of behavioral depression (Chau et al, 2001). According to this theory, local fluoxetine may alleviate behavioral depression in a manner analogous to a local M1 antagonist (Chau et al, 2001). Because relative ACh levels were recorded, it was not possible to determine whether basal ACh in experiments was elevated in the untreated behaviorally depressed animals and also whether fluoxetine normalized basal ACh; however, both of these phenomena were evident during the chronic fluoxetine experiment (Experiment 4), in which absolute ACh was recorded (see Figure 2).

The possibility that local fluoxetine decreases behavioral depression through a dopaminergic mechanism cannot be discounted (Nestler and Carlezon, 2006), because infusion of either 5-HT or a $5-\mathrm{HT}_{2}$ receptor antagonist into the NAc has been shown to increase DA outflow (Bowers et al, 2000; Parsons and Justice, 1993). It is interesting to note that acute and chronic fluoxetine treatment via systemic routes given to naïve (non-depressed) rats produced either no changes (Clark et al, 1996; Guan and McBride, 1988; Koch et al, 2002, 2004) or slight reductions (Clark et al, 1996; Ichikawa et al, 1998; Ichikawa and Meltzer, 1995) in DA outflow in the NAc. Moreover, systemic fluoxetine treatments either reduced or produced no change in the firing rates in DA neurons in the ventral tegmental area (Prisco and Esposito, 1995; Rodriguez-Landa et al, 2003). One study infused fluoxetine directly into the accumbens shell in Sprague-Dawley rats, but also found no changes in DA release (Bubar et al, 2003). Interestingly, however, in the Flinders sensitive line, an animal model of depression, in which basal DA is abnormally low and does not respond to 5-HT stimulation, antidepressant treatments have been shown to restore in these animals the ability of 5-HT to stimulate DA outflow (Zangen et al, 2001). Similarly, in the forced swim test, reduced escape motivation is linked to a reduction in accumbal DA outflow (Jaffe et al, 1993; Rossetti et al, 1993). Because DA has an important role in both approach and escape motivation, a reduction in DA activity following a swim probably contributes to behavioral depression (ie, decreased swimming time) in subsequent swims. Thus, one way fluoxetine could increase escape efforts in behaviorally depressed rats would be to normalize DA release. In the current study, DA was not studied together with $\mathrm{ACh}$; therefore, it was not possible to assess the relative contributions of dopaminergic $v s$ cholinergic mechanisms in the antidepressant effects of the local fluoxetine treatment. It is clear, however, that fluoxetine can counter the release of $\mathrm{ACh}$ and at the same time combat depression as measured in the swim test.

With regard to possible serotonergic and noradrenergic mechanisms, our previous data suggested that fluoxetine in the NAc suppresses extracellular ACh, in part, through stimulation of $5-\mathrm{HT}_{1 \mathrm{~A}}$ receptors but not $\beta$-adrenergic receptors (Rada et al, 1993). We have demonstrated in freely moving rats that (1) infusion of either fluoxetine or 5-HT into the NAc shell lowers extracellular ACh; (2) fluoxetine-induced decrease in extracellular ACh is blocked by co-infusion of propranolol, a mixed serotonergic $5-\mathrm{HT}_{1} /$ $\beta$-adrenergic receptor antagonist; (3) infusion of isoproterenol, an $\beta$-adrenergic receptor agonist, into the NAc shell has no measurable effect on extracellular ACh; and (4) systemic or local injection of $8-\mathrm{OH}-\mathrm{DPAT}$, a $5-\mathrm{HT}_{1 \mathrm{~A}}$ 
agonist, dose-dependently decreases extracellular ACh in the NAc shell (Rada et al, 1993).

Experiment 2 assessed whether fluoxetine has the ability to reduce extracellular ACh and to alleviate behavioral depression in the swim test when it is infused bilaterally (rather than unilaterally) in the NAc shell. Two major observations were made in this experiment: (1) fluoxetine given on day 3 decreased immobility and increased escape attempts, compared with Ringer given on day 2; and (2) no such differences occurred when fluoxetine and Ringer were given in the reversed order, that is, fluoxetine given the day before Ringer. The effect of day-3 fluoxetine was unlikely to be a factor of day because behavioral depression is usually worsened (and not lessened) after repeated exposure to the swim test. One explanation for the lack of difference between the effects of day-2 fluoxetine and day-3 Ringer could be that the fluoxetine treatment given resulted in an improvement in behavioral depression that lasted for $24 \mathrm{~h}$ or more, such that when tested again the following day, the same animals on Ringer emitted increased escape efforts as they did the day before during fluoxetine. Such lasting effects of local fluoxetine could have occurred due to the residual presence of either fluoxetine or its metabolite and/ or to long-lasting changes in the function of the local neural circuitry (eg, continued inhibition of ACh outflow). Another explanation could be that fluoxetine's action in the accumbens on day 2 prevented the animals from acquiring a conditioned behaviorally depressed response to the swim test the following day.

Experiment 3 demonstrated that local bilateral fluoxetine treatment does not affect activity in the open field. This finding suggested that the antidepressant effects of the local fluoxetine in Experiments 1 and 2 were due to the ability of the treatment to increase escape motivation rather than general activity.

It was suggested that the ability of acute drug administration to alleviate behavioral depression in the swim test might not mimic treatments given to human depressives, which normally take at least a week to produce noticeably results (Taylor et al, 2006). To strengthen the face validity of the swim test, Detke et al (1997) administered low doses (1$5 \mathrm{mg} / \mathrm{kg}$, s.c.) of fluoxetine daily for 2 weeks. These doses were initially ineffective but became effective after chronic administration. Experiment 4 used a similar method of fluoxetine administration. Our data indicating that such treatment increased escape efforts in the swim test are in agreement with the results of Detke et al (1997). Furthermore, our data regarding elevated basal extracellular ACh in the behavioral depressed control group are consistent with the study of Rada et al (2006). The novel finding in this study, however, is that such clinically relevant fluoxetine treatment normalizes the increase in basal extracellular ACh that followed the initial swim test 2 weeks later. This finding further implicates cholinergic transmission in the NAc as a potential target of action of SSRIs.

Regarding the experimental procedures themselves (eg, repeated handling and the daily injections), such procedures could have potentially contributed to the rise in basal $\mathrm{ACh}$ in the control animals. However, this scenario is unlikely because existing data regarding the effects of various stressors on ACh outflow in NAc are mixed, and the increases in ACh outflow due to such stressors were usually short lived (Imperato et al, 1991; Mark et al, 1996; Thiel et al, 1998), unlike the chronic elevation in basal ACh seen in the current study.

A discussion on the potential influence of the estrous cycle on the observed behavioral outcomes is appropriate because proestrous females are known to demonstrate shorter durations of immobility in the forced swim test than diestrous female rats (Pare and Redei, 1993). As vagina smears were not collected, the phase of the individual rat's estrous cycle at the time of experimentation was unknown. However, because all rats tested were born from different dams on different days and were housed individually in separate cages, their estrous cycles should have been randomly distributed and the effects of such estrous cycles on immobility scores should have been 'averaged out' across subjects within and between groups. Thus, it is likely that the estrous cycle was not a significant factor influencing the observed behavioral outcomes. This assumption is further supported by the observations that fluoxetine treatment alleviated behavioral depression in the swim test, but it did not affect locomotor activity in the open field.

In summary, the current data show that both acute, locally infused fluoxetine and chronic, subcutaneous fluoxetine injection lower extracellular ACh while simultaneously increasing escape efforts. In light of our current and past data (Rada et al, 1993; Chau et al, 2001), we propose that fluoxetine alleviates behavioral depression in the forced swim test, in part, through the following mechanisms. First, fluoxetine treatment elevates extracellular 5-HT in the NAc shell by blocking its reuptake (Rada et al, 1993). Second, elevated $5-\mathrm{HT}$, through its stimulation of the $5-\mathrm{HT}_{1 \mathrm{~A}}$ receptors, decreases or normalizes the elevation in $\mathrm{ACh}$ outflow from the local cholinergic interneurons during the behavioral depressed state (Rada et al, 1993). Finally, decreased ACh outflow in turn decreases cholinergic M1 receptor stimulation, thereby alleviating behavioral depression (Chau et al, 2001; Rada et al, 2006). Such intrinsic serotonergic and cholinergic mechanisms could potentially be one of the important targets of SSRI (and possibly other) treatments.

\section{ACKNOWLEDGEMENTS}

This research was supported by the USPHS Grant DA10608. We appreciate Dr Sarah Leibowitz at Rockefeller University in New York for assisting in the preparation of this article.

\section{DISCLOSURE}

The authors declare no conflict of interest.

\section{REFERENCES}

Avena NM, Bocarsly ME, Rada P, Kim A, Hoebel BG (2008). After daily bingeing on a sucrose solution, food deprivation induces anxiety and accumbens dopamine/acetylcholine imbalance. Physiol Behav 94: 309-315.

Avena NM, Rada P, Moise N, Hoebel BG (2006). Sucrose sham feeding on a binge schedule releases accumbens dopamine repeatedly and eliminates the acetylcholine satiety response. Neuroscience 139: 813-820. 
Bowers BJ, Henry MB, Thielen RJ, McBride WJ (2000). Serotonin 5 -HT receptor stimulation of dopamine release in the posterior but not anterior nucleus accumbens of the rat. J Neurochem 75: $1625-1633$.

Bubar MJ, McMahon LR, De Deurwaerdere P, Spampinato U, Cunningham KA (2003). Selective serotonin reuptake inhibitors enhance cocaine-induced locomotor activity and dopamine release in the nucleus accumbens. Neuropharmacology 44: 342-353.

Chau DT, Rada P, Kosloff RA, Taylor JL, Hoebel BG (2001). Nucleus accumbens muscarinic receptors in the control of behavioral depression: antidepressant-like effects of local M1 antagonist in the Porsolt swim test. Neuroscience 104: 791-798.

Clark RN, Ashby Jr CR, Dewey SL, Ramachandran PV, Strecker RE (1996). Effect of acute and chronic fluoxetine on extracellular dopamine levels in the caudate-putamen and nucleus accumbens of rat. Synapse 23: 125-131.

Descarries L, Gisiger V, Steriade M (1997). Diffuse transmission by acetylcholine in the CNS. Prog Neurobiol 53: 603-625.

Detke MJ, Johnson J, Lucki I (1997). Acute and chronic antidepressant drug treatment in the rat forced swim test model of depression. Exp Clin Psychopharmacol 5: 107-112.

Detke MJ, Rickels M, Lucki I (1995). Active behaviors in the rat forced swimming test differentially produced by serotonergic and noradrenergic antidepressants. Psychopharmacology (Berl) 121: $66-72$.

Dilsaver SC (1986). Cholinergic mechanisms in depression. Brain Res 396: 285-316.

Drossopoulou G, Antoniou K, Kitraki E, Papathanasiou G, Papalexi E, Dalla C et al (2004). Sex differences in behavioral, neurochemical and neuroendocrine effects induced by the forced swim test in rats. Neuroscience 126: 849-857.

Guan XM, McBride WJ (1988). Fluoxetine increases the extracellular levels of serotonin in the nucleus accumbens. Brain Res Bull 21: 43-46.

Hernandez L, Guzman NA, Hoebel BG (1991). Bidirectional microdialysis in vivo shows differential dopaminergic potency of cocaine, procaine and lidocaine in the nucleus accumbens using capillary electrophoresis for calibration of drug outward diffusion. Psychopharmacology (Berl) 105: 264-268.

Hoebel BG, Avena NM, Rada P (2007). Accumbens dopamineacetylcholine balance in approach and avoidance. Curr Opin Pharmacol 7: 617-627.

Ichikawa J, Kuroki T, Meltzer HY (1998). Differential effects of chronic imipramine and fluoxetine on basal and amphetamineinduced extracellular dopamine levels in rat nucleus accumbens. Eur J Pharmacol 350: 159-164.

Ichikawa J, Meltzer HY (1995). Effect of antidepressants on striatal and accumbens extracellular dopamine levels. Eur J Pharmacol 281: 255-261.

Imperato A, Puglisi-Allegra S, Casolini P, Angelucci L (1991). Changes in brain dopamine and acetylcholine release during and following stress are independent of the pituitary-adrenocortical axis. Brain Res 538: 111-117.

Jaffe EH, De Frias V, Ibarra C (1993). Changes in basal and stimulated release of endogenous serotonin from different nuclei of rats subjected to two models of depression. Neurosci Lett 162: $157-160$.

Janowsky DS, Risch SC, Gillin JC (1983). Adrenergic-cholinergic balance and the treatment of affective disorders. Prog Neuropsychopharmacol Biol Psychiatry 7: 297-307.

Johnson AM (1991). The comparative pharmacological properties of selective serotonin re-uptake inhibitors in animals. In: Feighner JP, Boyer WF (eds). Selective Serotonin Re-uptake Inhibitors: Perspectives in Psychiatry. John Wiley \& Sons, Inc.: New York, NY. Vol 1, pp 37-70.

Kirby LG, Lucki I (1997). Interaction between the forced swimming test and fluoxetine treatment on extracellular 5-hydroxytryptamine and 5-hydroxyindoleacetic acid in the rat. J Pharmacol Exp Ther 282: 967-976.

Koch S, Perry KW, Bymaster FP (2004). Brain region and dose effects of an olanzapine/fluoxetine combination on extracellular monoamine concentrations in the rat. Neuropharmacology 46: 232-242.

Koch S, Perry KW, Nelson DL, Conway RG, Threlkeld PG, Bymaster FP (2002). R-fluoxetine increases extracellular DA, $\mathrm{NE}$, as well as 5-HT in rat prefrontal cortex and hypothalamus: an in vivo microdialysis and receptor binding study. Neuropsychopharmacology 27: 949-959.

Lemberger L, Bergstrom RF, Wolen RL, Farid NA, Enas GG, Aronoff GR (1985). Fluoxetine: clinical pharmacology and physiologic disposition. J Clin Psychiatry 46(3 Part 2): 14-19.

Li YQ, Rao ZR, Shi JW (1989). Serotoninergic projections from the midbrain periaqueductal gray to the nucleus accumbens in the rat. Neurosci Lett 98: 276-279.

Mark GP, Rada P, Pothos E, Hoebel BG (1992). Effects of feeding and drinking on acetylcholine release in the nucleus accumbens, striatum, and hippocampus of freely behaving rats. J Neurochem 58: 2269-2274.

Mark GP, Rada PV, Shors TJ (1996). Inescapable stress enhances extracellular acetylcholine in the rat hippocampus and prefrontal cortex but not the nucleus accumbens or amygdala. Neuroscience 74: 767-774.

Mark GP, Weinberg JB, Rada PV, Hoebel BG (1995). Extracellular acetylcholine is increased in the nucleus accumbens following the presentation of an aversively conditioned taste stimulus. Brain Res 688: 184-188.

Meredith GE, Blank B, Groenewegen HJ (1989). The distribution and compartmental organization of the cholinergic neurons in nucleus accumbens of the rat. Neuroscience 31: 327-345.

Nestler EJ, Carlezon Jr WA (2006). The mesolimbic dopamine reward circuit in depression. Biol Psychiatry 59: 1151-1159.

Pare WP, Redei E (1993). Sex differences and stress response of WKY rats. Physiol Behav 54: 1179-1185.

Parsons LH, Justice Jr JB (1993). Perfusate serotonin increases extracellular dopamine in the nucleus accumbens as measured by in vivo microdialysis. Brain Res 606: 195-199.

Paxino G, Watson C (1997). The Rat Brain: in Stereotaxic Coordinates, 3 edn. Academic Press, Inc.: San Diego, CA.

Phelps PE, Vaughn JE (1986). Immunocytochemical localization of choline acetyltransferase in rat ventral striatum: a light and electron microscopic study. J Neurocytol 15: 595-617.

Prisco S, Esposito E (1995). Differential effects of acute and chronic fluoxetine administration on the spontaneous activity of dopaminergic neurones in the ventral tegmental area. $\mathrm{Br} J$ Pharmacol 116: 1923-1931.

Rada P, Colasante C, Skirzewski M, Hernandez L, Hoebel B (2006). Behavioral depression in the swim test causes a biphasic, longlasting change in accumbens acetylcholine release, with partial compensation by acetylcholinesterase and muscarinic-1 receptors. Neuroscience 141: 67-76.

Rada P, Mark GP, Pothos E, Hoebel BG (1991). Systemic morphine simultaneously decreases extracellular acetylcholine and increases dopamine in the nucleus accumbens of freely moving rats. Neuropharmacology 30: 1133-1136.

Rada PV, Hoebel BG (2001). Aversive hypothalamic stimulation releases acetylcholine in the nucleus accumbens, and stimulation-escape decreases it. Brain Res 888: 60-65.

Rada PV, Mark GP, Hoebel BG (1993). In vivo modulation of acetylcholine in the nucleus accumbens of freely moving rats: I Inhibition by serotonin. Brain Res 619: 98-104.

Rada PV, Mark GP, Taylor KM, Hoebel BG (1996). Morphine and naloxone, i.p. or locally, affect extracellular acetylcholine in the accumbens and prefrontal cortex. Pharmacol Biochem Behav 53: 809-816. 
Rodriguez-Landa JF, Contreras CM, Gutierrez-Garcia AG, Bernal-Morales B (2003). Chronic, but not acute, clomipramine or fluoxetine treatment reduces the spontaneous firing rate in the mesoaccumbens neurons of the rat. Neuropsychobiology 48: $116-123$.

Rossetti ZL, Lai M, Hmaidan Y, Gessa GL (1993). Depletion of mesolimbic dopamine during behavioral despair: partial reversal by chronic imipramine. Eur J Pharmacol 242: 313-315.

Shen HW, Hagino Y, Kobayashi H, Shinohara-Tanaka K, Ikeda K, Yamamoto $\mathrm{H}$ et al (2004). Regional differences in extracellular dopamine and serotonin assessed by in vivo microdialysis in mice lacking dopamine and/or serotonin transporters. Neuropsychopharmacology 29: 1790-1799.

Steinbusch HW (1981). Distribution of serotonin-immunoreactivity in the central nervous system of the rat-cell bodies and terminals. Neuroscience 6: 557-618.

Taylor MJ, Freemantle N, Geddes JR, Bhagwagar Z (2006). Early onset of selective serotonin reuptake inhibitor antidepressant action: systematic review and meta-analysis. Arch Gen Psychiatry 63: $1217-1223$.
Thiel CM, Huston JP, Schwarting RK (1998). Cholinergic activation in frontal cortex and nucleus accumbens related to basic behavioral manipulations: handling, and the role of posthandling experience. Brain Res 812: 121-132.

Van Bockstaele EJ, Chan J, Pickel VM (1996). Pre- and postsynaptic sites for serotonin modulation of GABA-containing neurons in the shell region of the rat nucleus accumbens. J Comp Neurol 371: 116-128.

Van Bockstaele EJ, Pickel VM (1993). Ultrastructure of serotoninimmunoreactive terminals in the core and shell of the rat nucleus accumbens: cellular substrates for interactions with catecholamine afferents. J Comp Neurol 334: 603-617.

Wong DT, Bymaster FP, Horng JS, Molloy BB (1975). A new selective inhibitor for uptake of serotonin into synaptosomes of rat brain: 3-(p-trifluoromethylphenoxy). N-methyl-3-phenylpropylamine. J Pharmacol Exp Ther 193: 804-811.

Zangen A, Nakash R, Overstreet DH, Yadid G (2001). Association between depressive behavior and absence of serotonin-dopamine interaction in the nucleus accumbens. Psychopharmacology (Berl) 155: 434-439. 